\title{
Clinical Profile of admitted children with malarial fever: a retrospective study
}

\author{
Tarakeswara Rao $\mathbf{P}^{1}$, Prudhvi $\mathbf{K}^{2}$ \\ ${ }^{1}$ Dr Pikala Tarakeswara Rao, Professor, ${ }^{2}$ Dr Prudhvi Krishna, Postgraduate, both authors are affiliated with Department \\ of Pediatrics, Maharaja Institute of Medical Sciences, Vizianagram, Andhrapradesh, India.
}

Address for Correspondence: Dr Pikala Tarakeswara Rao, Email: ptrao1971@gmail.com

\begin{abstract}
Introduction: Malaria continues to be a major public health problem in developing country like India. India contributes to $77 \%$ of the total malarial cases in Southeast Asia. Objective: The present retrospective study was conducted to find out the clinical profile in admitted pediatric patients of malarial fever. Methods: 108 hospitalized laboratory diagnosed malarial pediatric cases admitted to tertiary care hospital from 1st August 2013 to $30^{\text {th }}$ Nov 2015 were studied. Records of all the patients who were discharged with the diagnosis of malaria were retrieved, compiled and analyzed. Results: Plasmodium falciparum was commonest implicating agent found in 68 (63\%) of 108 children. Fever was the main presenting complains in all cases. Common clinical manifestations noted were organomegaly (63.9\%), pallor (43.5\%), altered sensorium (21.3\%), convulsions (18.5\%), clinical icterus (10.2\%) and circulatory collapse. Mortality occurred only in children below 5 years with Plasmodium falciparum malaria. Conclusion: Plasmodium falciparum infection is common infecting species. Multi organ involvement and severe manifestations commonly observed in falciparum infection. Simple febrile seizures and respiratory symptoms are common with vivax infection. Isolated tender hepatomegaly observed in $9.3 \%$ of patients. Mortality noted with plasmodium falciparum malaria in children below $5 \mathrm{yrs}$.
\end{abstract}

Key words: Malaria, clinical profile, plasmodium falciparum.

\section{Introduction}

Malaria is common parasitic infection causing high mortality and morbidity in children. Globally $69 \%$ of total malarial deaths are in children below 5 yrs of age in 2015 [1]. Mortality due to malaria in India is reported to be around $20.6 \%$ in pediatric age group. $60-65 \%$ of malaria in india is due to plasmodium falciparum and $35 \%$ are due to plasmodium vivax. It is caused by four different species of plasmodium. Severity of clinical manifestations varies with species causing the infection and age of the host. Traditionally severe clinical manifestations are usually reported with plasmodium falciparum. Few recent studies also reported severe manifestations with vivax malaria in children [2]. There is paucity of data of severe manifestations due to vivax in children. Most of the data on profile of severe malaria in children are reported from Africa and few from India [2,3]. The clinical features of malaria in children in endemic areas are nonspecific and vary significantly. The aim of our study was to find out the

Manuscript received: $4^{\text {th }}$ August 2016

Reviewed: $14^{\text {th }}$ August 2016

Author Corrected; $26^{\text {th }}$ August 2016

Accepted for Publication: $13^{\text {th }}$ September 2016 spectrum of clinical manifestations, infecting species, age distribution and mortality in admitted patients of malaria in our set up.

\section{Material and Methods}

The present retrospective observational study was conducted at Pediatric Department of tertiary care hospital of vizianagram. Case records of confirmed malaria patients admitted from $1^{\text {st }}$ August 2013 to $30^{\text {th }}$ November 2015 were retrieved from Medical Record Department and data was collected in a printed preformed proforma.

Permission from institutional research and ethical committee was taken before commencement of the study.

The diagnosis and confirmation of species of $\mathrm{P}$. falciparum and P. vivax malaria were obtained from the case sheets Diagnosis was done by thick and thin film of peripheral blood smear examination under oil 
immersion with Giemsa stain and Rapid diagnostic test. The inclusion and exclusion criteria for the study were as follow:

\section{Inclusion Criteria}

- Children in age group of below 14 years.

- Peripheral smear or rapid malaria antigen test (RMAT) positive for Plasmodium vivax and plasmodium falciparum malaria.

\section{Exclusion Criteria}

- Patient presenting with fever (Malarial parasite negative on peripheral smear and/or RMAT negative) but treated empirically like malaria.

A total of 108 hospitalized children below 14 yrs of age with positive peripheral smear or RMAT positive fulfilled the inclusion and exclusion criteria and were included in the study.

\section{Results}

Out of 108 children admitted with malaria 73(67.6\%) were males and 35(32.4\%) were female with male to female ratio 1:2 (Table-). Majority of children in the present study are under 5 years of age. $47.2 \%, 29.6 \%$ and $23.1 \%$ of children are infected with malaria in $<5 y$ rs, $5-10 y$ rs and 10-14 yrs age groups respectively.

The age of patients ranged from eight months to fourteen years with mean age of 4.5 years. In the present study $\mathrm{P}$. falciparum was the main infecting species in all age groups (Table-). Maximum malaria cases were due to $\mathrm{Pf}(63 \%)$; $\mathrm{PV}$ was documented in $17.6 \%$ and mixed infection in $19.4 \%$ cases.

Fever was the presenting complaint present in all the cases. Mean duration between appearance of the fever and admission was 6 days. Organomegaly was commonest clinical sign present in $63.9 \%$ of patients. Isolated splenomegaly and hepatomegaly was seen in $28.7 \%$ and $9.3 \%$ of children.

Hepatosplenomegaly was observed in $25.9 \%$ of cases. Pallor was second common clinical sign noted in $43.5 \%$ of children. Pallor was observed in thirty five cases of plasmodium falciparum malaria. Respiratory symptoms were seen more in Pv group while hemoglobinuria was common in Pf group (Table-).

Other clinical features noted were: impaired consciousness $(21.3 \%)$, convulsions (18.5\%), icterus (10.2\%), pain abdomen, cola colored urine (8.3\%). Of the 23 children with impaired consciousness, nineteen had multiple convulsions. Eleven children had hypotensive shock requiring ionotropic support. Out of 108 patients six patients died and two patients left against medical advice.

Table-1: Gender distribution of cases.

\begin{tabular}{|c|c|c|c|}
\hline Plasmodium species & Female & Male & TOTAL (Percentage) \\
\hline Plasmodium falcifarum & 19 & 49 & $68(63 \%)$ \\
\hline Plasmodium vivax & 8 & 11 & $19(17.6 \%)$ \\
\hline mixed & 9 & 12 & $21(19.4 \%)$ \\
\hline Total & $\mathbf{3 5}(\mathbf{3 2 . 4 \% )}$ & $\mathbf{7 3 ( 6 7 . 6 \% )}$ & $\mathbf{1 0 8}$ \\
\hline
\end{tabular}

Table-2: Age distribution of malarial cases.

\begin{tabular}{|c|c|c|c|c|}
\hline Age group & Pf & Pv & Mixed & Total \\
\hline$<5$ yrs & $32(29.6 \%)$ & $12(11.1 \%)$ & $7(6.5 \%)$ & $51(47.2 \%)$ \\
\hline $5-10 y r s$ & $23(21.3 \%)$ & $5(4.6 \%)$ & $4(3.7 \%)$ & $32(29.6 \%)$ \\
\hline$>10 y r s$ & $13(12 \%)$ & $2(1.9 \%)$ & $10(9.3 \%)$ & $25(23.1 \%)$ \\
\hline
\end{tabular}


Table-3: Clinical features of admitted malarial patients.

\begin{tabular}{|c|c|c|c|c|c|}
\hline Clinical features & $\mathbf{N}=\mathbf{1 0 8}$ & $\mathbf{P f}$ & $\mathbf{P v}$ & $\mathbf{P v} / \mathbf{P f}$ & $\mathbf{\%}$ \\
\hline Fever & 108 & 68 & 19 & 21 & $100 \%$ \\
\hline Pallor & 47 & 40 & 02 & 5 & $43.5 \%$ \\
\hline Splenomegaly & 31 & 22 & 05 & 4 & $28.7 \%$ \\
\hline Hepatomegaly & 10 & 09 & 0 & 01 & $9.26 \%$ \\
\hline Hepato Splenomegaly & 28 & 24 & 01 & 3 & $25.9 \%$ \\
\hline Icterus & 11 & 06 & 0 & 05 & $10.2 \%$ \\
\hline ALOC & 23 & 16 & 02 & 05 & $21.3 \%$ \\
\hline Convulsions & 20 & 11 & 04 & 05 & $18.5 \%$ \\
\hline shock & 11 & 07 & 0 & 04 & $10.2 \%$ \\
\hline Cola urine & 09 & 07 & 0 & 02 & $8.3 \%$ \\
\hline Resp.Symptoms & 15 & 04 & 09 & 02 & $13.9 \%$ \\
\hline Death & 06 & 06 & 0 & 0 & $5.5 \%$ \\
\hline
\end{tabular}

\section{Discussion}

Malaria continues to be common cause of morbidity and mortality in children. Globally $60 \%$ of clinical malarial cases and $80 \%$ of deaths occur in young children [4]. In the present study majority of children are under the age of 5 years $(47.2 \%)$. Clinical manifestations of malaria may be severe in infants and young children due to lack of partial immunity resulting due repeated malarial infections.

Boys were more affected than females in the present study with only $32.4 \%$ of females being affected. Kumari $\mathrm{M}$ et al. found similar results in their study with $34.0 \%$ girls were affected with malaria [5].

Plasmodium falcifarum is the most frequent implicating species accounting for $64 \%$ of cases. $\mathrm{P}$ vivax and mixed infections accounted for $17.6 \%$ and $19.4 \%$ of cases respectively. Study by $\mathrm{P}$ verma et al in 179 children observed $\mathrm{p}$ falcifarum malaria in $57.8 \%$ of cases and $\mathrm{p}$ vivax and mixed infection in $13.7 \%$ and $27.4 \%$ of children respectively [6]. In the present study $p$ falcifarum is common agent in all the age groups. This is in contrast to studies which have found high prevalence of $p$ vivax [7]. In the present study $p$ vivax is found in $17.6 \%$ of children. Species infecting the children may vary even in the same country because of different prevailing ecologic conditions resulting in breeding of different vectors. Study of prevalence of malaria in agency areas of Andhra Pradesh showed $\mathrm{p}$ falcifarum to be frequent infecting agent in all seasons [8].
Fever was the presenting complaint found in all the admitted cases. Mean duration of onset of fever and admission was 5 days. Similar observation were made by studies done by Taksande et al [9] and Kaushik et al [2].

Pallor in malaria is due to combination of multiple factors. Rapid destruction and removal of $\mathrm{RBC}$ by spleen and ineffective erythropoeisis is mainly responsible. Pallor was observed in 40(58.8\%) compared to $5(23.8 \%)$ of mixed infections. This correlated with finding of studies in Thailand where they found that likelihood of developing pallor was 1.8 times less in mixed malaria as compared to falcifarum malaria [10]. Pallor was noted in $96 \%$ of falcifarum malaria cases by Gohiya et al. in their study [11].

Organomegaly was noted in $63.9 \%$ of children. Enlargement of spleen alone and along with enlargement of liver was seen in 46/68 (67.6\%), 6/19 $(31.5 \%)$ and $7 / 21(21.4 \%)$ cases of $p$ falcifarum, $p$ vivax and mixed infections respectively. Enlargement of spleen is due vascular congestion and endothetial proliferation. High spleen palpable rate indicate high endemicity of malaria.

Majority of the patients enrolled in this study are drawn from high transmission areas of malaria. Splenomegaly was recorded in $59 \%$ of $\mathrm{P}$. vivax, $68.8 \%$ of $\mathrm{P}$. falciparum and $73.6 \%$ mixed $P$. infected patients in study of 502 malaria patients who are above $12 \mathrm{yrs}$ of 
age [12]. Hepatomegaly was tender in majority of cases and seen in $35.2 \%$ of cases. In 102 children below 12 yrs study splenomegaly was found in $97.16 \%$ of cases and hepatomegaly in $51.7 \%$ of cases by Saira Merchant et al [13]. Similar observation made by Gohiya P et al in 150 children of falcifarum malaria in children [11].

High colored urine found in $8.3 \%$ of patients. These children had history of intake of inadequate doses of quinine prescribed by local practitioners. In our study colacolored urine was observed in falcifarum and mixed infections.

Haemoglobinuria can also occur in patients with normal erythrocyte G6PD levels who receive quinine for severe malaria [14]. Cola coloured urine improved on treatment for malaria.

All the children who exhibited cola colored urination had clinical icterus. Icterus is found in $10.2 \%$ of children with falcifarum and mixed infection. Intravascular haemolysis contributing to these clinical observed features. Study done by Chaudhary et al observed icterus in $49 \%$ of cases which is quite high compared to our study [15].

Altered level of sensorium was found in $21.3 \%$ of children of which $18.5 \%$ had convulsions. Febrile seizures noted in vivax malaria below 5yrs. Rapid rise and higher fever trends are seen in vivax malaria due to lower fever threshold despite low parasitemia [16].

Respiratory symptoms (cough, distress) observed in 9/19 (47.3\%) of vivax malaria. Sequestration of P vivax infested RBC and greater inflammatory response to parasite leading to capillary alveolar dysfunction noted in vivax malaria [17]. This might perhaps explain respiratory manifestations observed in our study.

Death had occurred in 6 patients. All the patients were Plasmodium falcifarum positive and expired within $72 \mathrm{hrs}$ of admission. All the patients who expired had altered sensorium, severe anemia and shock.

\section{Conclusion}

$\mathrm{P}$ falcifarum malaria is still a major problem affecting the health of children in this area. Severe manifestations are observed with mono falcifarum malaria.

Respiratory manifestations are more commonly observed in vivax malaria whereas mixed infections are presenting with less severe symptoms.
Funding: Nil, Conflict of interest: Nil

Permission from IRB: Yes

\section{References}

1. World Malaria Report; Malaria in children under five. World Health Organisation [cited on 2016 apr 6]. Available from http: // www. who. Int / malaria / areas/ high_risk_groups/children/en./.

2. Kaushik JS, Gomber S, Dewan P. Clinical and epidemiological profiles of severe malaria in children from Delhi, India. J Health Popul Nutr. 2012 Mar; 30(1):113-6.

3. Yadav D, Chandra J, Aneja S, Kumar V, Kumar P, Dutta AK. Changing profile of severe malaria in north Indian children. Indian J Pediatr. 2012 Apr;79(4):483-7. doi: 10.1007/s12098-011-0603-x. Epub 2011 Nov 18.

4. World Malaria Report; Roll Back Malaria monitoring and evaluation. India country profile [Internet]. World Health Organisation [cited on 2014 Sept 6], 2005. Available from http: // www. rollbackmalaria. org/wmr 2005.html.

5. Kumari M, Ghildiyal R. Clinical Profile of Plasmodium vivax Malaria in Children and Study of Severity Parameters in relation to Mortality: Tertiary Care Centre Perspective in Mumbai, India. Malaria Research and Treatment. 2014; 2014:7656-57.

6. Verma P, Shukla US, Kalraiya A. Retrospective study on clinical profile of severe malaria in children admitted in a tertiary care centre of central India. People's J Sci Res 2014; 7(1):22-6.

7. Kochar DK, Das A, Kochar SK, Saxena V, Sirohi P, Garg S, Kochar A, Khatri MP, Gupta V. Severe Plasmodium vivax malaria: a report on serial cases from Bikaner in northwestern India. Am J Trop Med Hyg. 2009 Feb;80(2):194-8.

8. Raju MH, Ganesh N, Kumar KK, Sowjanya M, Satish PV, Sunita K. A study on prevalence of malaria in different mandals of east Godavari district,Andhra Pradesh,India.International Journal of Latest Research in Science and Technology. 2014; 3(6):74-77.

9.Takshande A, Vilhekar K, Jain M, Atkari S. Clinicohematological profile of cerebral malaria in a rural hospital. J Indian Acad Clin Med. 2006 Oct; 7: 308-12. 
10. Price RN, Simpson JA, Nosten F, Luxemburger C, Hkirjaroen L, ter Kuile F, Chongsuphajaisiddhi T, White NJ. Factors contributing to anemia after uncomplicated falciparum malaria. Am J Trop Med Hyg. 2001 Nov;65(5):614-22.

11. Gohiya P, Goel M, Dwevedi R, Renwal S. Clinical profile and prognostic indicators of Plasmodium Falciparum Malaria in children (1-12Years). International Journal of Medical Research and Review. 2014 Jun 30;2(03).

12. Rasheed A, Saeed S, Khan SA. Clinical and laboratory findings in acute malaria caused by various plasmodium species. J Pak Med Assoc. 2009 Apr; 59(4):220-3.

13. Saira M, Rajkumar MM, Mohammad MT: clinical manifestations and predictors of mortality in severe malaria in children.Sch. J. App. Med. Sci. June 2016; 4(6A):1931-35. Doi : 10.21276/sjams.2016.4.6.13.
14. Sodeinde O. Glucose-6-phosphate dehydrogenase deficiency. Baillieres Clin Haematol. 1992 Apr;5 (2): 367-82.

15. Taviad PP, Javadekar TB, Selot BA, Chaudhary VP. Socio Demographic and clinical features of the Malaria Cases. National Journal of community Medicine. 2012 Jan 1;3(1):94-6.

16. Zimmerman PA, Mehlotra RK, Kasehagen LJ, Kazura JW. Why do we need to know more about mixed Plasmodium species infections in humans? Trends Parasitol. 2004 Sep;20(9):440-7.

17. Anstey NM, Handojo T, Pain MC, Kenangalem E, Tjitra E, Price RN, Maguire GP. Lung injury in vivax malaria: pathophysiological evidence for pulmonary vascular sequestration and posttreatment alveolarcapillary inflammation. Journal of Infectious Diseases. 2007 Feb 15;195(4):589-96.

\section{How to cite this article?}

Tarakeswara Rao P, Prudhvi K. Clinical Profile of admitted children with malarial fever: a retrospective study. Int J Pediatr Res.2016;3(9):678-682.doi:10.17511/ijpr.2016.i09.09. 